\title{
Educational Protocol to Improve Pregnant Women Practices about Gestational Diabetes Mellitus
}

Sabah Abdou Hagrass"

Lecturer in Community Health Nursing Department, Faculty of Nursing, Zagazig University, Zagazig, Egypt

\begin{tabular}{ll}
\hline DOI: $\frac{10.36348 / \text { sjnhc.2019.v02i12.013 }}{\text { *Corresponding author: Sabah Abdou Hagrass }}$ & | Received: 20.12.2019 | Accepted: 27.12 .2019 | Published: 30.12 .2019
\end{tabular}

*Corresponding author: Sabah Abdou Hagrass

\section{Abstract}

Background: Gestational Diabetes Mellitus is considered to be a significant problem among pregnant women in Egypt. Aim: To evaluate the effect of educational protocol to improve pregnant women practices about gestational diabetes mellitus. Design: A quasi-experimental design was used. Setting: The outpatient diabetic clinic at Zagazig university hospital. Sample: A purposive sample of eighty pregnant diabetic women. Tools: Two tools were used in the study, Tool (1): Contained two parts; (1) demographic characteristics, (2) History about reproductive profile during pregnancy, Tool (2): Included two parts, assessment of knowledge of pregnant women about DM, and assessment of practice of pregnant women about DM. Results: The mean age of the pregnant women were $32.04 \pm 9.36$ years, also it was revealed that the total knowledge scores improved from $31.35 \%$ to $58.20 \%$, with a highly significant difference ( $\mathrm{p}=0.0044$ ) for the participants, additionally, the overall increase in adequate practices improved from 56 to $78.5 \%$ after the implementation of the protocol sessions, with a significant difference $(\mathrm{p}=0.0106)$. Conclusion: The implementation of educational protocol for pregnant women was effective and enhanced their practices, and knowledge regarding the gestational diabetes mellitus. Recommendation: The study recommended that further studies for pregnant women with gestational diabetes mellitus should be applied in all health care centers.

Keywords: Educational protocol, Pregnant Women, Gestational Diabetes Mellitus, and Practices.

Copyright @ 2019: This is an open-access article distributed under the terms of the Creative Commons Attribution license which permits unrestricted use, distribution, and reproduction in any medium for non-commercial use (NonCommercial, or CC-BY-NC) provided the original author and source are credited.

\section{INTRODUCTION}

Diabetes mellitus (DM), is considered to be a chronic metabolic disease that result from reduction in the production of insulin or sensitivity to insulin. The types of DM are; Type 1 diabetes that caused by the destruction in the production of insulin cells of pancreas, and Type 2 diabetes that is usually related to insensitivity or insufficient insulin production of cells [1].

Gestational diabetes mellitus (GDM) considered a case in which pregnant women that didn't have previous diagnosis with glucose intolerance exhibit high levels of blood glucose during pregnancy, especially in the $3^{\text {rd }}$ trimester [2]. GDM is a noncommunicable disease affecting pregnant women. The risk factors for GDM include advanced maternal, previous unexplained stillbirth and obesity [3]. Generally, the specific risks of the uncontrolled diabetes during pregnancy include many risks such as spontaneous abortion, fetal anomalies, preeclampsia, fetal demise, macrosomia, neonatal hypoglycemia, and neonatal hyperbilirubinemia [4].
Numerous epidemiological studies show that this disorder affects between 1 and $18 \%$ of pregnancies, depending on the ethnicity of the populations studied, the diagnostic criteria, or the BMI. Its incidence has been reported to be constantly rising. The prevalence of GDM in Egypt is $7.2 \%$, and in the USA it ranges from 3 to $7 \%$, depending on the population studied [5]. In women diagnosed GDM, glucose tolerance usually returns to its normal level after birth, but their risk of developing type 2 diabetes mellitus later in life is increased about 7-12 fold [6].

The management of GDM usually done for maintaining the level of blood glucose to its normal levels and approaches generally include monitoring of blood glucose \& lifestyle changes; When GDM is treated well, adverse infant outcomes such as macrosomia (weight > 4000gr), respiratory problems, special care admission and stillbirth are decreased [7]. 
In deed promoting healthy lifestyle interventions such as weight loss, do exercise, and eat healthy nutrition will decrease the risk of developing type 2 diabetes; also, follow up doctor appointments, and postpartum Oral Glucose Tolerance Test (OGTT), are important in early diagnosis and prevent of type 2 diabetes among women with GDM [8].

The chances to educate all women within reproductive age about diabetes can done through the educational protocols and programs on risks of unplanned pregnancies and improved maternal and fetal outcomes with pregnancy planning. Effective preconception counseling could avert substantial health and associated cost burdens in offspring. Family planning should be discussed, and effective contraception should be prescribed and used until a woman is prepared and ready to become pregnant [4].

The community health nursing plays an important role in enhancing knowledge and practices of individuals generally, and especially promotion of knowledge and practice of pregnant women about GDM due to the importance of these risky issues. Additionally, the community health nurses can standardize an educational programs orland protocols, including information about diagnosis, causes, management, and proper feeding in the period of pregnancy [9].

\section{Significance of the Study}

During the period of any pregnancy, there are some physiological changes that may be occur such as a certain degree of hyperinsulinemia and insulin resistance, but in some pregnant women these changes may lead to GDM; over the past 20 years, the prevalence of GDM has increased world-wide, and across Egypt [2]. In line with the 2030 Agenda, the Egyptian Government has launched a working plan called Egypt's Vision 2030, that is also known as Sustainable Development Strategy (SDS), that covered three dimensions; and in response to those dimensions, especially the environmental one; the aim of the study was to evaluate the effect of educational protocol in improving pregnant women practices about gestational diabetes mellitus.

\section{Hypothesis}

- It was hypothesized that educational protocol improves the knowledge and practice regarding gestational diabetes mellitus among pregnant women.

Research Aim: Was to evaluate the effect of educational protocol to improve pregnant women practices about gestational diabetes mellitus.
This aim was full filled through the following objectives:

- Assess knowledge and practices of pregnant women about gestational diabetes mellitus.

- Design an educational protocol for pregnant women to enhance their knowledge and practice about gestational diabetes mellitus.

- Evaluate the effect of the sessions for the pregnant women about gestational diabetes mellitus.

\section{METHODS}

Design: A quasi-experimental design was conducted.

Study Setting: In outpatient diabetic clinic at Zagazig university hospital.

\section{Sample Size}

It was done and calculated by using the "EPI info (Epidemiological information system)" software version six; the calculated sample was eighty pregnant women; those purposive subjects were chosen according to the following criteria.

\section{Inclusion Criteria}

- Prime gravid and Multiparty.

- $\quad$ Age 20-40 years.

\section{Excluded Criteria}

Women With:

- Cardiac orland respiratory illnesses.

- Fetal that has any congenital malformations.

- Multiple pregnancies.

- Ante partum hemorrhages.

Tools for Data Collection: Two tools were developed by the researchers:

Tool (1): Consisted of two parts:

First Part: Included information about demographic characteristics (such as age, education, occupation, family size and income).

Second Part: History about reproductive profile during pregnancy.

Tool (2): included two parts; (1): consisted of assessment of knowledge of pregnant women about DM (definition, symptoms of diabetes mellitus, natural level of sugar in blood, types of DM, management for DM and the complications of topical insulin injection during pregnancy, and healthy diet and exercise during pregnant(pre and post format), and (2): consisted of assessment of practices of DM control and management; assessed the practices of the respondents with regard to the way in which they demonstrate their knowledge through their actions such as preparation of insulin dose, and steps to take a blood sample for the 
analysis of sugar. These questions covered intervention and diabetic management. (.pre and post format) Scores were used to evaluate participant's knowledge and practices of diabetes mellitus during pregnancy.

The scoring for the questions were; one degree for correct answer and zero degree for wrong or no answer.

- The total scores that equal to $60 \%$ or more than considered adequate or satisfactory knowledge and practice

- The total scores that less than $60 \%$ considered inadequate or unsatisfactory knowledge

\section{Validity \& Reliability}

The tools were translated into Arabic language, then reviewed by five experts (three from community health nursing department and the remaining two experts were from obstetrics \& Gynecology nursing department) who conducted face and content validity of all item. All recommended modifications were performed. The reliability of precision alpha was $88 \%$ from the research subjects and practice.

\section{Pilot Study}

It was carried out on about ten percentage of the sample size for evaluating the clarity and applicability of the tools after their development.

\section{Field Work}

- The researcher conducted an intensive review of the past and current related literature covering various aspects of the "Gestational Diabetes Mellitus" and associated knowledge and practice for pregnant women. This was done using available textbooks and articles in scientific periodicals and journals. Based on this review, the tools were prepared in their preliminary forms, and reviewed by a panel of nursing and medical specialists for face and content validation. The review also helped in developing a basic framework of the educational protocol.

- Informed oral consent was obtained from the participants.

- The researcher met with the subjects, introduced her-self and explained the purpose of the study to obtain their consent to participate in the study and gain their cooperation and confidence.

- The participants were interviewed individually before applying the planned sessions to collect the baseline data using all study tools.

- The researcher started to fill-out the questionnaire from the studied sample. The researcher read and explained each item to the pregnant women and recorded their responses to each item. This interview took about 25 to 30 minutes.

- The execution of the study was done through 4 phases, namely assessment, planning, implementation, and evaluation. This lasted for 7 months and half from the first of April 2019 to the end of October 2019.

- The objective of the protocol was to improve knowledge, and practice, of the pregnant women.

- The protocol was implemented in the form of 9 sessions. The duration of each session ranged between thirty minutes and forty-five minutes. The protocol was implemented in small homogeneous groups in the diabetic outpatient clinic; each group consisted of 5-10 pregnant women according to their attendance. The sessions were administered twice per week for each study group. They were held on Saturdays, and Wednesdays.

- The protocol was implemented through various teaching methods as short lectures, group discussions, brain storming, demonstration redemonstration, and role-play. The teaching media included power-point presentations and a handbook.

- Each session was started by a summary about what was given through the previous session and the objectives of the new one to make sure that pregnant women recognize the content, and use simple words to suit the educational level of the pregnant women. Motivation and reinforcement techniques as praise and recognition were used during the session to enhance participation and learning.

- The researcher designed an illustrative booklet in simple Arabic language to be distributed to pregnant women.

\section{Description of the Protocol}

- General objective of the program: Was to improve knowledge, and practices of the pregnant women about gestational diabetes mellitus.

\section{Specific Objectives}

\section{By the end of this Program}

- The pregnant women will be able to discuss simple information about gestational diabetes mellitus.

- The pregnant women will be able to summarize the main causes, risk factors and complications of gestational diabetes mellitus.

- The pregnant women will be able to deal correctly with their problem.

The protocol sessions consisted of two main components:

- The first component was for giving a theoretical background of gestational diabetes mellitus such as definition, causes, effects and risk factors, complications, and management; (this included 3 sessions)

- The second main component was for giving practical sessions about practices of pregnant women regarding gestational diabetes mellitus, such as preparation of insulin dose, self-monitoring 
of glucose level (this included 4 sessions).

- There were 2 sessions for starting and ending the protocol sessions.

\section{Evaluation Phase}

- Immediately after the end of the sessions. Evaluation was done to assess the impact of the protocol.

\section{Ethical Considerations}

- Anonymity, confidentiality and privacy of the pregnant women were assured.

- Voluntary participation and right to refuse to participate in the study was emphasized to the subjects.

- Verbal consent was taken at the beginning of the study from the subjects.

\section{Administrative Design}

A formal letter was taken from Faculty of Nursing, Zagazig University to the director of outpatient clinics at Zagazig University hospital to get approval for collection the data.

\section{Statistical Design}

The responses of the participants from the questionnaires were collated and analyzed descriptively using the Microsoft Excel 2010 program. Copies of the questionnaire are available from the first author on request. The data were revised, coded tabulated and analyzed using Epi info version 6.1 programs.

\section{RESULTS}

Table-1 demonstrated socio-demographic characteristics of subjects. it pointed out that the mean age of the pregnant women were $32.04 \pm 9.36$ years. Also $41.25 \%$ of the pregnant women had secondary education. Also $70.0 \%$ pregnant women were housewife. However $46.3 \%$ pregnant women had family size from 5 to 6 , while $(57.5 \%)$ pregnant women had not enough income.

Table-2 illustrated the reproductive profile of pregnant women's during pregnancy; about $100 \%$ of the pregnant women in the study said they had at least one pregnancy. From those, $70(87.5 \%)$ became pregnant 1 or 2 times, and $10(12.5 \%)$ have there or more than three times. No one of the pregnant women had more than 5 pregnancies. Concerning parity, five $(27.8 \%)$ were nulliparous, that is, they became pregnant but had an abortion, and the other 75 (93.7\%) experienced one to four deliveries. according to type of delivery, $(45.3 \%)$ pregnant women have normal vaginal delivery. While, the reason for C-section, only four $(9.8 \%)$ haven't any reason related to DM.

Fig-1 the figure described the pregnant women total knowledge scores before and after the implementation of the educational protocol. According to the figure, it is known that the total percentage of the adequate knowledge about diabetes was improved from $31.35 \%$ to $58.20 \%$, with a highly significant difference $(\mathrm{p}=0.0044)$ for the participants.

Fig-2 the figure described the pregnant women total practices scores before and after the implementation of the educational protocol. According to the figure, the present study revealed that the overall increase in adequate practices improved from 56 to $78.5 \%$ after the implementation of the protocol sessions, with a significant difference $(\mathrm{p}=0.0106)$.

Table-1: Distribution of studied pregnant women according to their characteristics, $(n=80)$

\begin{tabular}{|c|c|c|}
\hline Items & Number & Percent \\
\hline $\begin{array}{l}\text { Age (in years) } \\
20-25 \\
26-35 \\
36-40\end{array}$ & $\begin{array}{l}39 \\
30 \\
11 \\
\end{array}$ & $\begin{array}{l}48.75 \\
37.5 \\
13.75 \\
\end{array}$ \\
\hline $\mathrm{x} \pm \mathrm{SD}$ & \multicolumn{2}{|c|}{$32.04 \pm 9.36$} \\
\hline $\begin{array}{l}\text { Education } \\
\text { Illiterate } \\
\text { Primary/preparatory } \\
\text { Secondary } \\
\text { University }\end{array}$ & $\begin{array}{l}13 \\
22 \\
33 \\
12\end{array}$ & $\begin{array}{l}16.2 \\
27.50 \\
41.25 \\
15.00\end{array}$ \\
\hline $\begin{array}{l}\text { Occupation } \\
\text { House wife } \\
\text { Worker } \\
\end{array}$ & $\begin{array}{l}66 \\
24 \\
\end{array}$ & $\begin{array}{l}82.5 \\
17.5 \\
\end{array}$ \\
\hline $\begin{array}{l}\text { Family size } \\
2 \text { to } 4 \\
5 \text { to } 6 \\
6-8\end{array}$ & $\begin{array}{l}16 \\
37 \\
27\end{array}$ & $\begin{array}{l}20.0 \\
46.3 \\
33.7\end{array}$ \\
\hline $\begin{array}{l}\text { Income } \\
\text { Not enough } \\
\text { Enough } \\
\text { More enough }\end{array}$ & $\begin{array}{c}46 \\
25 \\
9 \\
\end{array}$ & $\begin{array}{c}57.5 \\
31.2 \\
11.25 \\
\end{array}$ \\
\hline
\end{tabular}


Table-2: Distribution of pregnant women according to their reproductive profile during pregnancy, $(\mathrm{n}=80)$

\begin{tabular}{|c|c|c|}
\hline Items & umber & Percent \\
\hline $\begin{array}{l}\text { Number of pregnancies }(\mathbf{n}=\mathbf{8 0}) \\
1-2 \\
3-5\end{array}$ & & $\begin{array}{l}87.5 \\
12.5\end{array}$ \\
\hline $\begin{array}{l}\mathrm{N}^{\circ} \text { of abortions }(\mathrm{n}=18) \\
1 \\
2\end{array}$ & & $\begin{array}{l}72.2 \\
27.8\end{array}$ \\
\hline $\begin{array}{l}\text { History of parity }(n=80) \\
N^{0} \text { of births }(n=75) \\
1 \text { to } 2 \\
3 \text { to } 4\end{array}$ & & $\begin{array}{l}84.0 \\
16.0\end{array}$ \\
\hline $\begin{array}{l}\text { Delivery types }(\mathbf{n = 7 5}) \\
\text { Normal } \\
\text { C-section } \\
\text { Normal \& C-section }\end{array}$ & & $\begin{array}{c}45.3 \\
43.75 \\
13.75\end{array}$ \\
\hline $\begin{array}{l}\text { C-sections' reasons }(\mathbf{n}=\mathbf{4 1}) \\
\text { Indirect or directly related to diabetes } \\
\text { Not related to diabetes }\end{array}$ & & $\begin{array}{c}90.2 \\
9.8\end{array}$ \\
\hline
\end{tabular}

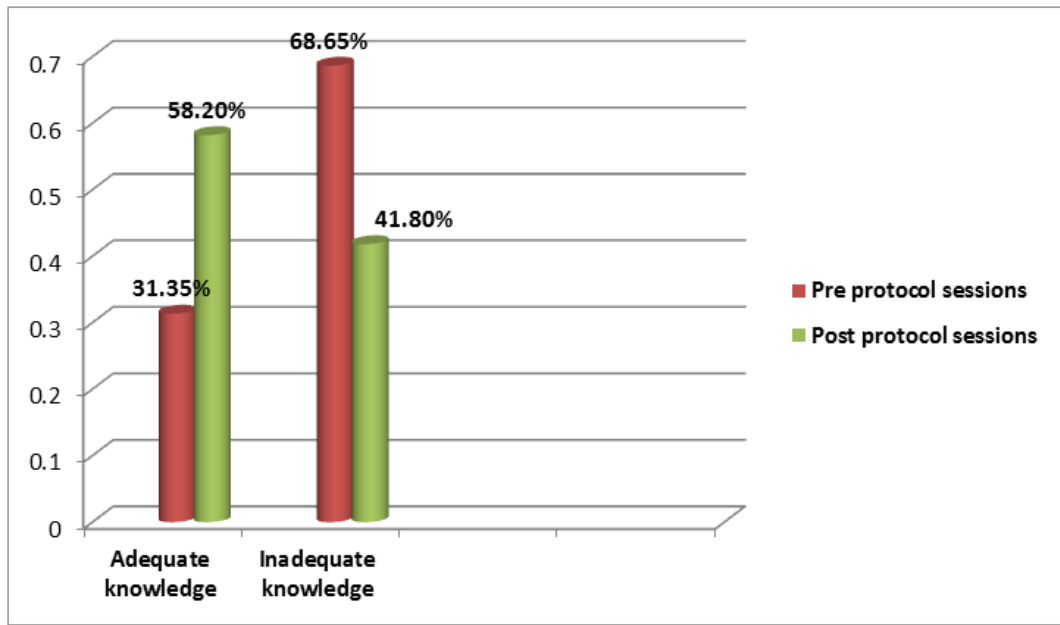

Fig-1: Pregnant women total knowledge scores before and after the implementation of the educational protocol, $(\mathrm{n}=\mathbf{8 0})$

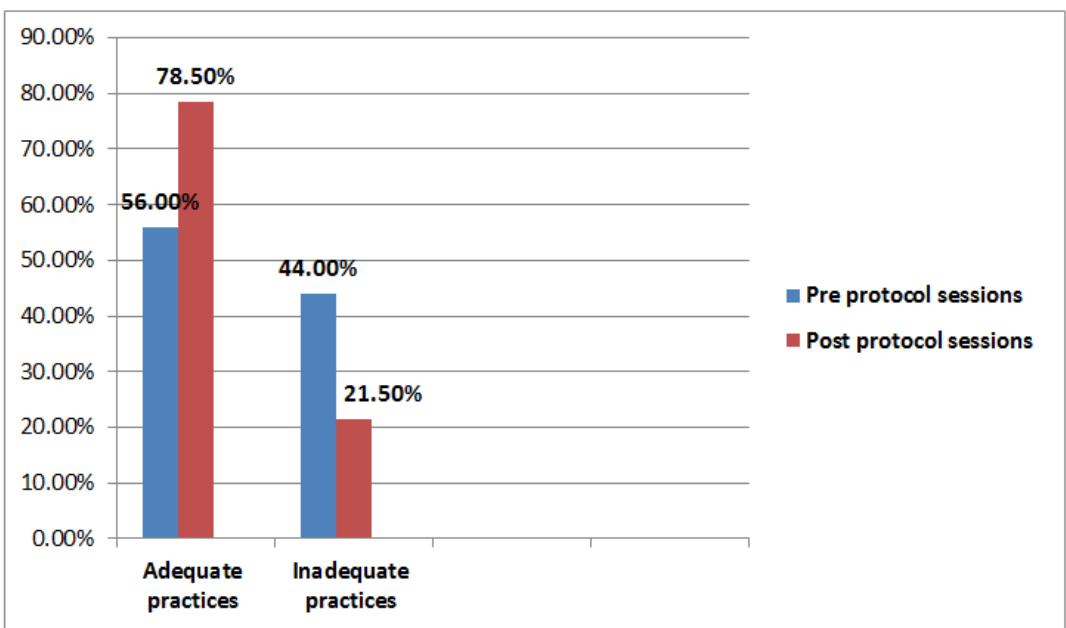

Fig-2: Pregnant women total practices scores before and after the implementation of the educational protocol, $(\mathrm{n}=\mathbf{8 0})$

\section{DISCUSSION}

Gestational diabetes mellitus (GDM) affects pregnant women worldwide; and it usually occurs when the function of pancreas becomes insufficient to overcome the diabetogenic environment in pregnancy's period and then causes high level of blood glucose due to the body's high demand of insulin. Many factors like: nutrition, obesity, ethnicity, age historical family, 
history of DM in lasts pregnancies, essential hypertension or pregnancy-related hypertension, the history of spontaneous abortions, or unexplained stillbirths cause an increased risk of blood glucose intolerance levels among pregnant women [10].

Regarding the socio-demographic characteristics of the studied subjects; the current study; the current study showed that the mean age of the pregnant women were $32.04 \pm 9.36$ years. Also $41.25 \%$ of the pregnant women had secondary education. Also $70.0 \%$ pregnant women were housewife.

This finding disagreed with Carolan-Olah \& Sayakhot [7], in their study at a large Melbourne metropolitan hospital in Australia; as they mentioned that one third of their subjects had completed a bachelor degree, but the same researchers agreed with the present study on reporting that approximately half of women in their research were unemployed. Additionally, Kolivand et al., [12], agreed with the current results as they reported in their study in Iran that most of their participants were housewives.

Another finding of the present study was that more than half of the pregnant women had not enough income. On the same line, Padmini et al., [13] highlighted in their Indian study that approximately more than half $(51 \%)$ of their participants were of low socioeconomic status.

Related to the reproductive profile of pregnant women's during pregnancy at the present study; the current results illustrated that the reproductive profile of pregnant women's during pregnancy. It was known that the majority of the pregnant women became pregnant one or two times, and about $(12.5 \%)$ of them had there or more times. No one of them had more than five times of pregnancies. Concerning parity, nearly one third of the pregnant women were nulliparous, that is, they became pregnant but had an abortion, and the majority of them experienced 1 to 4 deliveries. according to type of delivery, (45.3\%) pregnant women have normal vaginal delivery. While, the reason for $\mathrm{C}$-section, only four $(9.8 \%)$ haven't any reason related to DM.

This result disagreed with Kusemwa et al., [14], in their results at Chitungwiza Central Hospital Antenatal Clinic, in Zimbabwe; as they reported the majority of their participants were pregnant for one time. Also, this result was disagreed with Andrew et al., [15], in their screening for gestational diabetes mellitus; as they revealed that most of their women had C-section as a type of delivery.

Additionally, the present results agreed with Moura et al., [16] in their reasesrch; in which they mentioned that the majority of their studied women with DM, and also $56(52.8 \%)$ reported at least one pregnant time.
The focused caring for pregnant women with GDM should be knowledgeable about the maternal and fetal risks related to the disorder, antepartum maternal and fetal assessment, use of obstetric ultrasound to monitor fetal growth and well-being, decision-making about timing and route of delivery, intrapartum obstetric and glycemic management, and postpartum assessment and counseling [17].

Regarding pregnant women total knowledge scores before and after the implementation of the educational protocol; the current results pointed out that the total percentage of adequate knowledge about diabetes increased from $31.35 \%$ to $58.20 \%$, with a highly significant difference $(\mathrm{p}=0.0044)$ for the participants.

This inadequate level of knowledge before the sessions could be explained by the women's low educational level in the current study (secondary level of education) as mentioned before, and also might be due to the reduction in health educational programs and protocols in the governmental settings generally.

Fortunately, these inadequate results of pregnant women's knowledge regarding GDM were improved after the implementation of the educational sessions of the protocol; these good amendments in the level of the participant's knowledge could elucidate the favorable impact of the educational sessions and how the subjects were interested and cooperative within the intervention of the protocol and also with the researcher.

These results of the current study was in the same line with Alayoub et al., [18], in their study to assess the effect of a multidisciplinary group intervention delivered by a specialist midwife and dietitian on women's knowledge of GDM, in Ireland; as they pointed out that there was a significant improve in the score of median regarding to knowledge that followed their educational sessions (pre-sessions score 8 (-2-12); post-sessions score $12(1-12)$; $\mathrm{p}<0.001)$ among their subjects.

Additionally, Kusemwa et al., [14], were in the same line with the current results in their research at Chitungwiza Central Hospital Antenatal Clinic, in Zimbabwe; as they said that Knowledge of GDM among the subjects of the study was very poor, but it improved after their intervention.

On other hand, the current results disagreed with Appajigol, and Bellary [19], in their study in India; as they mentioned that their participants were aware about knowledge of GDM in totally.

Regarding pregnant women total practices scores before and after the implementation of the educational protocol; the present study revealed that the 
overall increase in adequate practices improved from 56 to $78.5 \%$ after the implementation of the protocol sessions, with a significant difference $(\mathrm{p}=0.0106)$.

This improvement in the results of pregnant women practices reflexed the positive effect of the educational protocol and also the high level of the participants' obligation during the study period; furthermore, it reflexed how the subjects were interested and cooperative in the study.

These present results agreed with VargasTerrones et al., [20], in their study in Spain, as they mentioned that improvement in practices of women in the form of Physical exercise has the potential to prevent the excessive gestational weight gain, GDM and the other complications that usually associated with obesity in pregnancy.

Also, the results were in the same line with Guo et al., [21], in their Chinese study for increasing the effect of lifestyle programs about the prevention of gestational diabetes; as they revealed that practices in the form of nutrition and exercise within pregnancy were preventive of GDM (RR 0.77 , 95\% CI [0.69; 0.87]).

Additionally, Carolan-Olah [11], was at the same line with our current results in the study done in College of Health and Biomedicine, Victoria University; as the researcher concluded that Interventions of practices which included adopting a low glycemic index feeding and the high levels of activities appeared to be successful at decreasing maternal blood glucose levels and decreasing the insulin requirements within pregnancy.

On other hand, the current results disagreed with Appajigol, and Bellary [19], in their study in India; as they mentioned that their participants had good practices towards gestational diabetes mellitus.

\section{CONCLUSION}

The study findings led to the conclusion that the pregnant women had inadequate knowledge, and inadequate practices regarding the gestational diabetes mellitus before the protocol. Fortunately, the implementation of educational protocol was effective and enhanced their practice, and knowledge regarding the gestational diabetes mellitus.

\section{RECOMMENDATIONS}

Based on the results of this study, it is highly recommended that:

- Replication of the current study on a long probability sample is recommended to achieve generalization and wider utilization of the designed program.

- Establishing a specialized diabetes clinic in all health centers to guide the pregnant women about preventive measures and caring of diabetes mellitus .

- Further researches are needed to assess long term effects of such program.

\section{ACKNOWLEDGEMENTS}

We would like to thank all the pregnant women who participated in the study and staff of the out patients diabetic clinic at Zagazig University Hospitals for their help and cooperation during the study period.

\section{REFERENCES}

1. Coton, S., Nazareth, I., \& Petersen, I. (2016). A cohort study of trends in the prevalence of pregestational diabetes in pregnancy recorded in UK general practice between 1995 and 2012. BMJ Open. 6(1):e009494.

2. Xu, T., He, Y., Dainelli, L., Yu, K., Detzel, P., Silva-Zolezzi, I., Volger, S., \& Fang, H. (2017). Healthcare interventions for the prevention and control of gestational diabetes mellitus in China: a scoping review. Journal of BMC Pregnancy and Childbirth. 17(1):171-200.

3. Larrabure-Torrealva, G., Martinez, S., LuqueFernandez, M., Sanchez, S., Mascaro, P., Ingar, H., Castillo, W., Zumaeta, R., Grande, M., Motta, V., Pacora, P., Gelaye, B., \& Williams, M. (2018). Prevalence and risk factors of gestational diabetes mellitus: findings from a universal screening feasibility program in Lima, Peru. Journal of BMC Pregnancy and Childbirth. 18(1):303-320.

4. American Diabetes Association. (2019). Management of Diabetes in Pregnancy: Standards of Medical Care in Diabetes-2019. Diabetes Care 2019. 42(1):S165-S172.

5. Fathy, W., Khalil, N., \& Mahmoud, N. (2018). Risk factors for gestational diabetes mellitus among pregnant women attending Monshaat Sultan Family Health Center, Menoufia Governorate. Menoufia Med Journal. 31(1):640645.

6. Bennett, C., Walker, R., Blumfield, M., Gwini, S., Ma, J., Wang, F., Wan, Y., Dickinson, H., \& Truby, H. (2018). Interventions designed to reduce excessive gestational weight gain can reduce the incidence of gestational diabetes mellitus: A systematic review and metaanalysis of randomized controlled trials. Diabetes Research and Clinical Practice Journal. 23(1): 3-22.

7. Carolan-Olah, M., \& Sayakhot, P. (2018). A randomized controlled trial of a web-based education intervention for women with Gestational Diabetes Mellitus. Journal of Midwifery. 34(5):125.

8. Sayakhot, P., Carolan-Olah, M., \& Steele, C. (2016). Use of a web-based educational intervention to improve knowledge of healthy diet and lifestyle in women with Gestational Diabetes Mellitus compared to standard clinic-based 
education. Journal of BMC Pregnancy Childbirth. 16(1): 208-222.

9. Marshall, K. (2017). Community Education for Women with Gestational Diabetes. Journal of obstetric, Gynecological and Neonatal Nursing Practices. 46(3):S10.

10. Morampudi, S., Balasubramanian, G., Gowda, A., Zomorodi, B., \& Patil, A. (2017). The Challenges and Recommendations for Gestational Diabetes Mellitus Care in India: A Review. Journal of Front Endocrinol. 14(4):123-143.

11. Carolan-Olah, M. (2016). Educational and intervention programmes for gestational diabetes mellitus (GDM) management: An integrative review. Elsevier Journal. 23(1):103-114.

12. Kolivand, M., Keramat, A., Rahimi, M., Motaghi, Z., Shariati, M., \& Emamian, M. (2018). Self-care Education Needs in Gestational Diabetes Tailored to the Iranian Culture: A Qualitative Content Analysis. Iran Journal Nursing Midwifery Res. 23(3):222-229.

13. Padmini, A., Kamalam, M., Thakor, G., \& Ranjita, M. (2008). A Community-Based Diabetes Prevention and Management Education Program in a Rural Village in India. Journal of Diabetes Care. 31(6):1100.

14. Kusemwa, P., Mukona, D., Zvinavashe, M., Dodzo, L., \& Makoni, P. (2018). Knowledge of Gestational Diabetes Mellitus and Self Care Practices in Pregnancy. Journal of Diabetes and Metabolic Research. 3(1):26-34.

15. Andrew, J., Caroline, A., Philippa, C., \& Shepherd, M. (2017). Screening for gestational diabetes mellitus based on different risk profiles and settings for improving maternal and infant health. Journal of Cochrane library. 2(43):1-23.
16. Moura, E., Evangelista, D., \& Damasceno, A. (2012). The knowledge of women with diabetes mellitus regarding preconception care and maternal-fetal risks. Rev Esc Enferm USP. 46(1):22-8.

17. Caughey, A. (2019). Gestational diabetes mellitus: Obstetric issues and management. Online article. Retrieved from: https://www.uptodate.com/contents/gestationaldiabetes-mellitus-obstetric-issues-andmanagement. Accessed on: 13\12\2019.

18. Alayoub, H., Curran, S., Coffey, M., Hatunic, M., \& Higgins, M. (2018). Assessment of the effectiveness of group education on knowledge for women with newly diagnosed gestational diabetes. Irish Journal of Medical Science (1971), 187(1), 65-68.

19. Appajigol, J., \& Bellary, S. (2015). Knowledge and practices of rural family physicians and obstetricians towards gestational diabetes mellitus. International Journal of Community Medicine and Public Health. 2(2):153-155.

20. Vargas-Terrones, M., Nagpal, T., \& Barakat, R. (2019). Impact of exercise during pregnancy on gestational weight gain and birth weight: an overview. Brazilian Journal of Physical Therapy. 23(2):164-169.

21. Guo, X., Shu, J., Fu, X., Chen, X., Zhang, L., Ji, M., Liu, X., Yu, T., Sheng, J., \& Huang, H. (2018). Improving the effectiveness of lifestyle interventions for gestational diabetes prevention: a meta-analysis and meta-regression. $A n$ International Journal of Obstetrics \& Gynaecology. 12(5):123-140. 